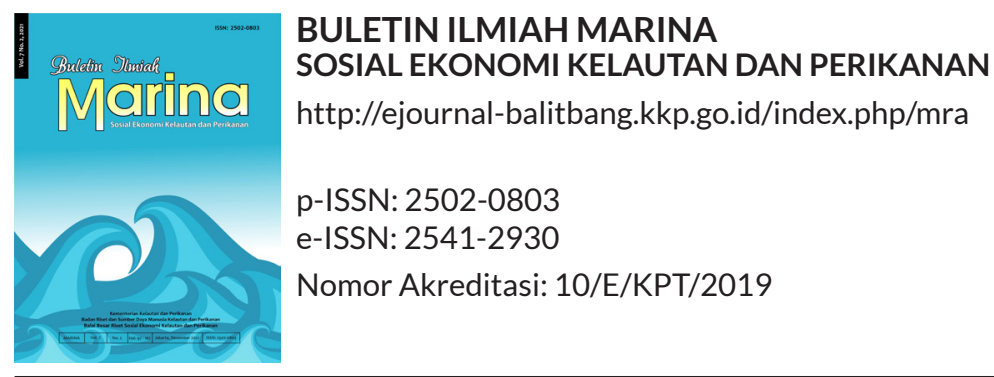

\title{
Kinerja Rantai Pasok dan Manajemen Logistik Komoditas Udang di Kabupaten Indramayu, Jawa Barat
}

\section{Supply Chain Performance and Logistic Management of Shirmp in Indramayu District, West Java}

\author{
${ }^{*}$ Risna Yusuf, Asnawi, Rismutia Hayu Deswati, dan Lathifatul Rosyidah \\ Balai Besar Riset Sosial Ekonomi Kelautan dan Perikanan Gedung BRSDM KP I Lt. 4 \\ JIn. Pasir Putih I, Ancol Timur, Jakarta Utara, Indonesia \\ Telp: (021) 64711583 Fax: 64700924
}

Diterima tanggal: 1 November 2021; Diterima setelah perbaikan: 17 Desember 2021;

Disetujui terbit: 30 Desember 2021

\begin{abstract}
ABSTRAK
Kabupaten Indramayu merupakan salah satu kabupaten yang memiliki potensi budi daya udang yang cukup besar. Penelitian ini bertujuan untuk menganalisis kinerja rantai pasok dan manajemen logistik komoditas udang di Kabupaten Indramayu, Jawa Barat. Survei dilakukan pada bulan April-Juni 2019. Pengumpulan data primer dilakukan melalui wawancara dengan menggunakan kuesioner kepada pembudi daya udang, pengumpul, dan pedagang besar, kemudian data dianalisis secara deskriptif. Hasil penelitian menunjukkan bahwa kinerja rantai pasok komoditas udang di Kabupaten Indramayu, Jawa Barat dapat dilihat dengan 2 (dua) indikator, yaitu efektivitas dan efisiensi. Indikator efektivitas menunjukkan bahwa kinerja rantai pasok udang di Provinsi Jawa Barat mengalami peningkatan dari sisi produksi sekitar $18,45 \%$. Hal ini menunjukkan pasokan udang di Kabupaten Indramayu dapat memenuhi permintaan UPI udang yang ada di Jawa Barat. Pasokan udang di Indramayu sebagian besar didistribusikan ke wilayah DKI Jakarta, Jawa Timur, dan sekitarnya. Indikator efisiensi dilihat dari disparitas harga antar waktu dan margin harga. Disparitas harga terbesar terjadi pada ukuran udang $\mathrm{S} 100$, yaitu sebesar $6 \%$, disparitas harga terkecil terjadi pada udang dengan ukuran S70, yaitu sebesar $3 \%$. Margin harga yang terjadi pada setiap simpul dalam rantai pasok udang. Margin harga untuk ukuran udang S170 pada pedagang kecil 3\% dan pengecer 22\%. Pada ukuran udang S100, margin harga yang terjadi adalah pedagang kecil $4,3 \%$ dan pedagang besar $2 \%$. Selain itu, biaya distribusi komoditas udang yang dikeluarkan masih tinggi sehingga perlu perbaikan dalam sistem manajemen rantai pasok komoditas udang melalui perbaikan sarana prasarana produksi, distribusi, dan penyimpanan yang dilakukan secara terintegrasi untuk menghasilkan jaminan komoditas udang secara efektif dan efisien.
\end{abstract}

Kata Kunci: kinerja rantai pasok; manajemen logistik; efektif; efisiensi; udang vaname; Kabupaten Indramayu; Jawa Barat

\begin{abstract}
Indramayu Regency is one of the regencies that has large enough cultivation potential. This study aimed to analyze the supply chain performance and logistics management of shrimp commodities in Indramayu Regency, West Java. The survey was conducted from April to June 2019. Primary data collection was conducted through interviews with shrimp farmers, middlemen, and wholesalers using a questionnaire, and the data were analyzed using a descriptive method. The results showed that the supply chain performance of shrimp commodities in Indramayu Regency, West Java, can be seen with 2 (two) indicators, namely effectiveness and efficiency. The effectiveness indicator show that the performance of the shrimp supply chain in West Java Province has increased from the production side around $18.45 \%$. This is show that shrimp supply in Indramayu Regency can meet the demand for shrimp UPI in West
\end{abstract}


Java. Most of the shrimp supply in Indramayu distribute to DKI Jakarta, East Java, and surrounding areas. Efficiency indicator showed from the price disparity over time and the price margin. The highest price disparity occurs in the size of shrimp S100, which is 6\%, the lowest price disparity occurs in shrimp with size 570 , which is $3 \%$. The price margin occurred at each node in the shrimp supply chain. Price margin for shrimp size S170 is 3\% for small traders and 22\% for retailers. At S100 shrimp size, the price margin occurred is $4.3 \%$ for small traders and $2 \%$ for wholesalers. On the other hand, the distribution costs of shrimp commodities are still high. Therefore, it is necessary to improve the shrimp commodity of supply chain management system by production, distribution, and storage facilities that are carried out in an integrated manner to produce a guarantee of shrimp commodities effectively and efficiently.

Keywords: supply chain performance; logistics management; effective, efficiency, vannamei shrimp; Indramayu Regency; West Java

\section{PENDAHULUAN}

\section{Latar Belakang}

Kabupaten Indramayu merupakan salah satu kabupaten di Jawa Barat yang memiliki potensi budi daya cukup besar. Pemanfaatan lahan-lahan eks tambak udang windu dan eks tambang pasir besi untuk usaha pembesaran udang vaname (sistem tradisional, tradisional plus, semi intensif, dan intensif), menjadikan wilayah ini sebagai salah satu daerah penghasil komoditas budi daya udang vaname di Provinsi Jawa Barat. Hal ini terlihat pada produksi perikanan budi daya komoditas udang Kabupaten Indramayu yang mencapai $54.969,53$ ton pada tahun 2018 dan kontribusi produksi perikanan Kabupaten Indramayu terhadap Provinsi Jawa Barat pada tahun 2017 sebesar 310.573,23 ton atau sebesar $26,76 \%$. Tujuan pemasaran udang vaname Kabupaten Indramayu dilakukan ke wilayah Provinsi Jawa Barat dan wilayah lainnya seperti Jakarta, Jawa Tengah, dan Yogyakarta (Zamroni et al., 2019). Pemasaran udang vaname ini tentunya tidak lepas dari sistem rantai pasok dan manajemen logistik yang memiliki nilai tambah lebih besar, pemasaran yang lebih efisien serta menguntungkan (Untsayain et al., 2017).

Rantai pasok merupakan rangkaian hubungan antar perusahaan atau aktivitas yang melaksanakan penyaluran pasokan barang atau jasa dari tempat asal sampai ke tempat pembeli atau pelanggan (Assauri, 2011) dan sampai konsumen akhir dengan kondisi yang lebih baik dan menguntungkan (Ongirwalu et al., 2015). Supply chain menyangkut hubungan yang terusmenerus mengenai barang, uang, dan informasi untuk memenuhi kebutuhan konsumen (Apriani et al., 2019) yang dilakukan setiap anggota rantai pasok untuk memenuhi tujuan akhir rantai pasok (Vorst, 2006). Keberhasilan dalam sebuah usaha dicapai apabila rantai kegiatan dari mulai penyediaan bahan baku hingga produk sampai ke tangan konsumen akhir terkelola dengan baik; pengelolaan rantai pasok ini dikenal dengan istilah manajemen rantai pasok (Syahputra et al., 2018) dan dapat memenuhi kebutuhan konsumen lokal dan luar negeri (Siahaya, 2013).

Manajemen rantai pasok/supply chain management (SCM) merupakan sebuah sistem pendekatan total untuk mengelola seluruh aliran informasi, bahan, dan jasa dari bahan baku (Chase \& Jacobs, 2001) yang mengantarkan produk ke konsumen akhir dengan menggunakan teknologi informasi untuk mengoordinasikan semua elemen supply chain dari mulai pemasok ke pengecer, lalu mencapai tingkat berikutnya yang merupakan keunggulan kompetitif yang tidak tersedia di sistem logistik tradisional (Fitzsimmons \& Fitzsimmons, 2006). Manajemen rantai pasok ini memerlukan suatu tahapan proses mulai dari perencanaan, pelaksanaan, dan pengendalian operasi rantai pasokan (Stevenson, 2009).

Sistem logistik merupakan hal yang sangat penting dalam pemasaran komoditas ini, sistem logistik sebagai bagian dari rantai pasok (supply chain) yang menangani arus barang, informasi, dan uang melalui proses pengadaan (procurement), penyimpanan (warehousing), transportasi (transportation), distribusi (distribution), dan pelayanan pengantaran (delivery services) (Peraturan Presiden Republik Indonesia Nomor 26 Tahun 2012 [Perpres Nomor 26 Tahun 2012], 2012) serta membahas mengenai keterkaitan antara entitas/pelaku dalam sebuah kegiatan logistik yang terintegrasi dan dapat menjamin kelancaran komoditas udang secara efektif dan efisien (Yusuf et al., 2020) dari pemasok hingga konsumen dalam masing-masing distribusi untuk menggerakkan barang/jasa (Anonymous, 2013) serta didukung oleh jaringan informasi dan komunikasi yang efisien (Mulyadi, 2011). 
Permasalahan sistem logistik komoditas perikanan di Indonesia adalah masih tingginya biaya logistik sebagai akibat dari struktur pasar oligopoli dan biaya distribusi ditentukan oleh pelaku usaha yang dominan (Tajerin et al., 2015). Selain itu, permasalahan dalam penyediaan ikan untuk memenuhi konsumsi disebabkan oleh dukungan sistem logistik yang belum optimal, kualitas pelayanan yang belum memadai ditandai dengan jalur distribusi yang panjang dan tidak efisien, serta infrastruktur logistik yang kurang memadai (Deswati \& Muhadjir, 2015). Persaingan internasional semakin ketat, baik antar produk, perusahaan, dan rantai pasok, serta negara (Heizer \& Render, 2014). Hal ini memerlukan manajemen logistik yang baik sehingga dapat meningkatkan kinerja logistik (Harimurti, 2017) dengan biaya distribusi lebih efisien (Yusuf \& Hikmayani, 2017). Biaya logistik yang rendah dan tepat waktu (Apriliani et al., 2020) serta arus distribusi dapat dilakukan secara efektif dan efisien (Rosyidah et al., 2020).

Penelitian ini bertujuan untuk menganalisis kinerja rantai pasok dan manajemen logistik komoditas udang di Kabupaten Indramayu, Jawa Barat. Kinerja rantai pasok dilihat dari efektivitas dan efisiensi rantai pasok komoditas udang, sedangkan manajemen logistik dilihat dari perdagangan, sistem penyimpanan, dan sistem transportasi.

\section{Pendekatan IImiah}

Penelitian ini dilakukan pada bulan AprilJuni 2019. Lokasi penelitian yang telah dipilih adalah Kabupaten Indramayu, Jawa Barat. Kabupaten Indramayu dipilih sebagai lokasi penelitian karena daerah ini memiliki potensi budi daya udang dan menjadi salah satu daerah pasokan udang di Jawa Barat.

Metode pengumpulan data yang digunakan dalam penelitian ini adalah metode survei. Wawancara dilakukan kepada responden dengan menggunakan kuesioner sebagai instrumen pengumpulan data. Jumlah responden dalam penelitian ini sebanyak 80 orang yang terdiri atas pembenih 13 orang, pembudi daya 60 orang, dan pedagang 7 orang. Pemilihan responden dilakukan secara purposive random sampling. Metode analisis data dilakukan secara deskriptif yang bertujuan untuk menyederhanakan data agar lebih mudah dipahami (Nazir \& Muhammad, 1988). Rantai pasok dilakukan dengan memetakan rantai dalam input produksi (pakan, benih, dan saprokan) hingga distribusi udang ke pembudi daya, pedagang sampai konsumen akhir. Selanjutnya, persentase dihitung berdasarkan jumlah pasokan dari simpul awal yang didistribusikan ke simpul selanjutnya pada komoditas udang. Kinerja rantai pasok komoditas udang dihitung dengan menggunakan indikator efektivitas rantai pasok yang dilihat dari kriteria ketersediaan, yaitu melihat seberapa besar permintaan dan berapa yang dipenuhi (pasokan) untuk memenuhi permintaan tersebut dan efisiensi rantai pasok yang dilihat dari indikator disparitas harga dengan aspek disparitas harga antar waktu dan indikator margin harga pada setiap simpul (Kementerian Perdagangan, 2011).

\section{PERKEMBANGAN BUDI DAYA UDANG VANAME DI KABUPATEN INDRAMAYU}

Tabel 1 menggambarkan tentang perkembangan produksi budi daya udang vaname baik dilihat dari volume, nilai, dan harga. Hal ini digunakan sebagai referensi untuk menganalisis kinerja rantai pasok dan manajemen logistik komoditas udang di Kabupaten Indramayu.

Perkembangan produksi budi daya udang vaname selama delapan tahun dari tahun 2013 sampai dengan 2020 mengalami kenaikan dengan rata-rata pertumbuhan $5,60 \%$ per tahun. Nilai produksi rata-rata mengalami penurunan sebesar $-0,24 \%$ per tahun. Pada tahun 2014, produksi mengalami kenaikan sebesar 2,19\%, tetapi nilai produksi mengalami penurunan sebesar $7,85 \%$, yang disebabkan pada tahun 2014 terjadi penurunan harga sebesar $9,82 \%$.

Perkembangan harga selama delapan tahun dari tahun 2013 sampai dengan 2020 secara rata-rata mengalami penurunan sebesar $3,96 \%$ per tahun, tahun 2013-2014 mengalami penurunan sebesar 9,82\%, dan tahun 2014-2015 mengalami penurunan sebesar 2,37\%. Harga mulai cenderung naik kembali pada tahun 2016 dan 2017, yaitu tahun 2015-2016 harga naik sebesar 2,64\%, dan tahun 2016-2017 naik sebesar 2,54\%, serta tahun $2017-2018$ naik sebesar $71,64 \%$. Namun, sejak tahun 2019 sampai dengan tahun 2020, harga udang vaname turun sebesar $35,76 \%$ dan $56,65 \%$.

\section{PROFIL RANTAI PASOK KOMODITAS UDANG DI KABUPATEN INDRAMAYU}

Pembudi daya atau pelaku usaha pembesaran udang vaname yang memiliki keunggulan bersaing menyebabkan performa usaha 
dari budi daya tersebut juga akan semakin baik (Deswati et al., 2020). Pelaku usaha pembesaran udang di Jawa Barat terdiri dari 3 (tiga) kategori, yaitu pembudi daya tradisional, pembudi daya semi intensif, dan pembudi daya intensif. Kegiatan usaha budi daya udang membutuhkan input produksi pakan, benih, dan saprokan. Ketiga input produksi tersebut memberikan kontribusi yang berbeda kepada pembudi daya. Input produksi pakan memberikan kontribusi terbesar pada pembudi daya intensif sebesar $84 \%$ dan pembudi daya semi intensif sebesar $16 \%$, tetapi tidak memberikan kontribusi sama sekali pada pembudi daya tradisional. Input produksi benih memberikan kontribusi terbesar pada pembudi daya intensif sebesar $62 \%$, pembudi daya semi intensif $28 \%$, dan pembudi daya tradisional sebesar $10 \%$. Pada proses pembenihan, setiap 1 (satu) indukan akan menghasilkan telur induk sebanyak 200 ribu sampai 300 ribu ekor. Induk tersebut bertelur sebanyak 6-8 kali selama 3 (tiga) bulan, kemudian induk tersebut diganti. Benih yang dijual adalah benih dengan ukuran post larva (PL) 10 yang masa pembenihannya selama 18 hari. Perusahaan ini memiliki 26 bak dengan volume produksi mencapai 550 ton, per bulan menghasilkan 30-40 juta ekor/ bulan atau 350—450 juta ekor/tahun. Benih udang vaname dari pembenih yang berada di lokasi Kabupaten Indramayu sebesar $40 \%$ diperuntukkan untuk memenuhi permintaan pasar Jawa Tengah dan Yogyakarta, sebesar 30\% untuk memenuhi permintaan Provinsi Jawa Barat (Indramayu, Cirebon, Garut, dan Karawang), serta masingmasing sebesar $10 \%$ dipasok ke Kabupaten Pacitan Provinsi Jawa Timur, Sumatra, dan Banten.

Input produksi berupa sarana produksi perikanan sebesar $60 \%$ kontribusinya untuk pembudi daya intensif, $25 \%$ untuk pembudi daya semi intensif, dan $15 \%$ untuk pembudi daya tradisional. Pakan sebesar $16 \%$ kontribusi untuk pembudi daya semi intensif dan $84 \%$ untuk pembudi daya intensif. Pembudi daya intensif menjual hasil panen dengan cara negosiasi dengan pembeli (pengumpul besar) secara langsung, yang selanjutnya pembeli melakukan pemanenan di tambak bersama tim panennya. Pembudi daya tradisional menjual udang ke pedagang kecil yang selanjutnya oleh pedagang kecil udang tersebut dijual ke pengecer dan pasar. Persentase terbesar penjualannya adalah ke pasar, yaitu sebesar $78 \%$ dan sisanya $22 \%$ ke pengecer yang selanjutnya oleh pengecer udang tersebut dijual ke pasar lokal (Gambar 1).

Pemasaran udang vaname di Kabupaten Indramayu dilakukan oleh pedagang dengan berbagai tingkatan. Peran pedagang ini menjadi sangat penting karena penetapan harga udang umumnya ditentukan oleh pedagang karena adanya informasi harga dan jaringan dengan konsumen baik UPI maupun rumah tangga. Beberapa kategori

Tabel 1. Produksi Budi Daya Udang Vaname di Kabupaten Indramayu, Jawa Barat Tahun 2013-2020.

\begin{tabular}{|c|c|c|c|c|c|c|c|c|c|}
\hline \multirow{2}{*}{$\begin{array}{c}\text { Produksi } \\
\text { Harga } \\
\text { Udang }\end{array}$} & \multicolumn{8}{|c|}{ Tahun } & \multirow{2}{*}{$\begin{array}{c}\text { Rata- } \\
\text { rata } \\
\text { Pertum- } \\
\text { buhan/ } \\
\text { Tahun } \\
\text { (\%) }\end{array}$} \\
\hline & 2013 & 2014 & 2015 & 2016 & 2017 & 2018 & 2019 & 2020 & \\
\hline $\begin{array}{l}\text { Vaname } \\
\text { (Ton) }\end{array}$ & $43.078,26$ & $44.020,55$ & $47.632,50$ & $48.722,21$ & $61.413,99$ & $54.969,99$ & $55.602,62$ & $61.071,16$ & \\
\hline $\begin{array}{l}\text { NaikTurun } \\
(\%)\end{array}$ & & 2,19 & 8,21 & 2,29 & 26,05 & $-10,49$ & 1,15 & 9,84 & $4 \quad 5,60$ \\
\hline $\begin{array}{c}\text { Nilai } \\
(\text { Rp000) }\end{array}$ & 2.308.973.473 & 2.127.668.120 & 2.247.653.782 & 2.359.219.696 & 3.049 .195 .564 & 4.684.530.300 & 3.048.432.752 & 1.451.399.137 & \\
\hline $\begin{array}{l}\text { Naik/urun } \\
(\%)\end{array}$ & & $-7,85$ & 5,64 & 4,96 & 29,25 & 53,63 & $-34,93$ & $-52,39$ & $9-0,24$ \\
\hline $\begin{array}{l}\text { Harga } \\
\text { (Rp/Kg) }\end{array}$ & 53.600 & 48.334 & 47.187 & 48.422 & 49.650 & 85.220 & 54.825 & 23.766 & \\
\hline $\begin{array}{l}\text { Naik/unun } \\
\text { (\%) }\end{array}$ & & $-9,82$ & $-2,37$ & 2,64 & 2,54 & 71,64 & $-35,67$ & $-56,65$ & $5-3,96$ \\
\hline
\end{tabular}

Sumber: Dinas Kelautan dan Perikanan Kabupaten Indramayu, 2018; BPS Kabupaten Indramayu, 2020; BPS Kabupaten Indramayu, 2021 
pedagang yang ada di Kabupaten Indramayu, antara lain,

a. Pedagang besar atau supplier, biasanya sudah berbentuk CV atau PT yang sudah memiliki fasilitas lengkap seperti cold storage, armada transportasi, dan kotak penyimpanan, bahkan di beberapa pedagang juga memiliki pabrik es sendiri. Kapasitas penjualan sudah besar, minimal 24,5 ton per hari dan disalurkan ke UPI. Kapasitas penyimpanan cukup besar akan lebih memudahkan proses produksi (Sutanto \& Sumarauw, 2014).

b. Pedagang kecil, sama halnya dengan pedagang besar atau supplier, namun berskala lebih kecil, kapasitas penjualan maksimal $1-1,5$ ton. Fasilitas yang dimiliki pun lebih sederhana, biasanya hanya berupa keranjang dan box sedangkan armada transportasi berupa mobil pick up. Biasanya udang yang dijual melalui pengumpul ini adalah udang yang ukurannya tidak diterima oleh UPI atau untuk konsumsi lokal (ukuran >100).

c. Pedagang pengecer, yaitu pedagang yang menjual udang vaname ke pasar lokal dengan konsumen rumah tangga dan restoran dalam jumlah yang sedikit.

\section{KINERJA RANTAI PASOK KOMODITAS UDANG DI KABUPATEN INDRAMAYU}

\section{Efektivitas}

Efektivitas rantai pasok udang di Kabupaten Indramayu, Provinsi Jawa Barat mengalami peningkatan dari sisi produksi, yaitu tahun 2016 mencapai $48.722 .210 \mathrm{~kg}$ dan 2017 sebesar $61.413 .990 \mathrm{~kg}$ serta permintaan UPI pada tahun 2016 di wilayah Jawa Barat sebesar 8.990.000 kg. Hal ini menunjukkan bahwa $18,45 \%$ pasokan udang di Kabupaten Indramayu dapat memenuhi permintaan UPI udang yang ada di Jawa Barat. Pasokan udang dari Indramayu sebagian besar didistribusikan ke wilayah DKI Jakarta, Jawa Timur, dan sekitarnya.

\section{Efisiensi}

Efisiensi rantai pasok berdasarkan indikator disparitas harga yang dilihat dari data harga antar waktu awal tahun, tengah tahun, dan akhir tahun diperoleh bahwa disparitas harga terbesar terjadi pada ukuran udang $\$ 100$, yaitu sebesar $6 \%$, sedangkan disparitas harga terkecil terjadi pada udang dengan ukuran S70, yaitu sebesar 3\%. Margin harga terjadi pada setiap simpul dalam rantai pasok udang. Berdasarkan hasil analisis, Provinsi Jawa Barat memiliki 2 (dua) rantai pasok udang dari pembesaran, yaitu Rantai Pertama, pedagang kecil $\rightarrow$ pengecer $\rightarrow$ pasar lokal. Ukuran udang yang dijual dengan ukuran S170; dan Rantai Kedua, pembesaran $\rightarrow$ pedagang kecil $\rightarrow$ pedagang besar $\rightarrow$ UPI. Ukuran udang yang diperjualbelikan adalah lebih banyak pada ukuran S100. Berdasarkan hasil tersebut maka margin harga untuk ukuran udang $\mathrm{S} 170$ adalah pedagang kecil $3 \%$ dan pengecer $22 \%$. Pada ukuran udang $\mathrm{S} 100$, margin harga yang terjadi adalah pedagang kecil $4,3 \%$ dan pedagang besar $2 \%$.

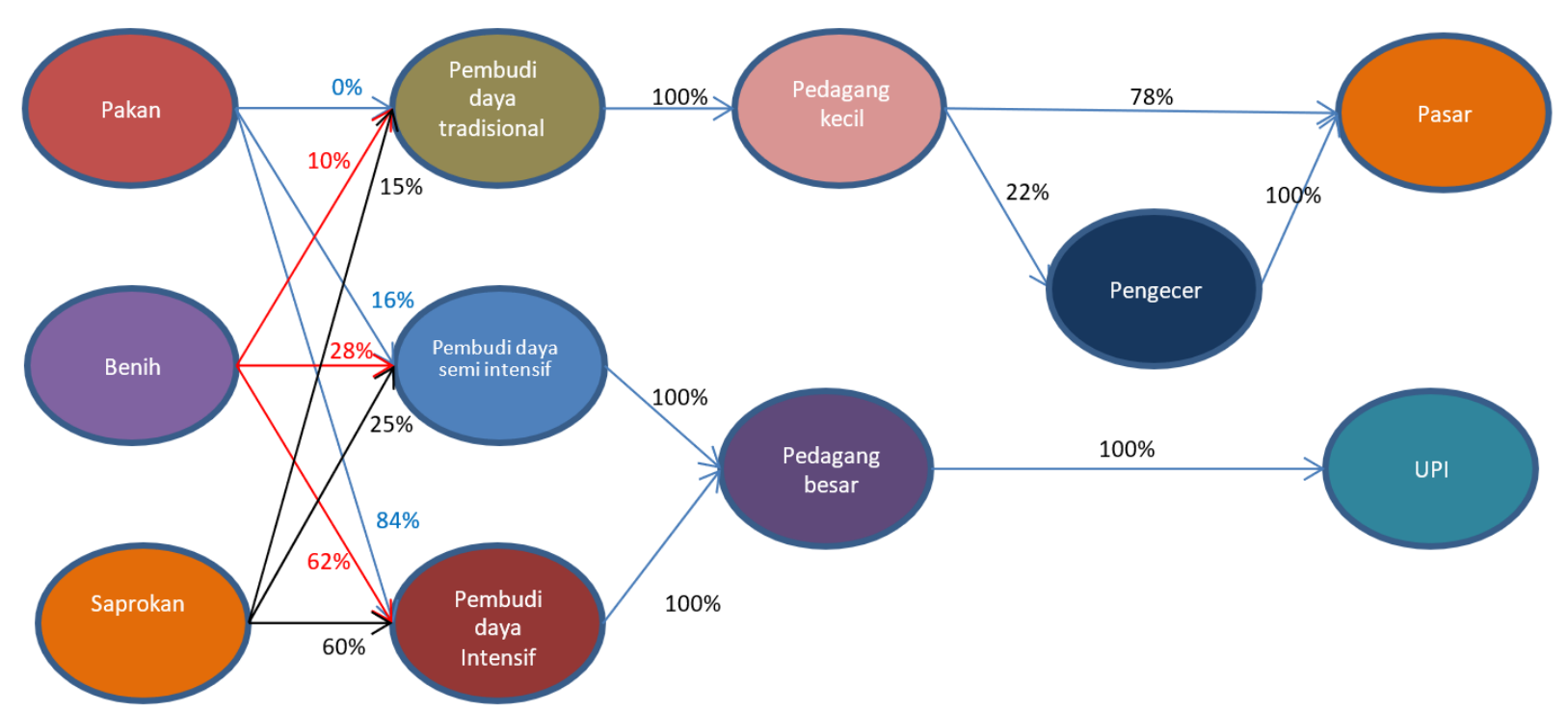

Gambar 1. Rantai Pasok Komoditas Udang di Indramayu, Jawa Barat Sumber: Data Primer Diolah, 2019 
Tabel 2. Efisiensi Rantai Pasok Udang di Provinsi Jawa Barat, 2019.

\begin{tabular}{lll}
\hline Indikator & \multicolumn{1}{c}{ Kriteria } & \multicolumn{1}{c}{ Kinerja } \\
\hline $\begin{array}{l}\text { Disparitas } \\
\text { Harga }\end{array}$ & Disparitas & $\begin{array}{l}\text { 6\% pada udang } \\
\text { S100, 3\% pada } \\
\text { udang S70 }\end{array}$ \\
$\begin{array}{ll}\text { Margin } \\
\text { Harga }\end{array}$ & Harga udang & $\begin{array}{l}\text {-Konsumen pasar } \\
\text { dengan udang S170: } \\
\text { untuk: }\end{array}$ \\
& -Konsumen & $\begin{array}{l}\text { pedagang kecil 3\%, } \\
\text { pengecer 22\% }\end{array}$ \\
& pasar & -UPI dengan ukuran \\
& udang S100: peda- \\
& gangkecil 4,3\%, ped- & agang besar 2\%. \\
\hline
\end{tabular}

Sumber: Data Primer Diolah, 2019

\section{MANAJEMEN LOGISTIK KOMODITAS UDANG}

Manajemen logistik merupakan suatu proses koordinasi mulai dari perdagangan, penyimpanan, transportasi, dan distribusi barang yang terintegrasi antara sisi hulu dan sisi hilir sehingga dapat diperoleh gambaran yang lebih detail mengenai kinerja supply chain (Subroto et al., 2015) dengan fungsi produksi, pemasaran, dan distribusi ke pelanggan berjalan lancar agar bisa memenuhi kebutuhan pelanggan. Dengan terpenuhinya kepuasan pelanggan dapat meningkatkan keunggulan produk yang dihasilkan perusahaan (Nuraini et al., 2021).

\section{Perdagangan}

\section{Pembenihan}

Pada sistem logistik pembenihan udang akan dibahas terkait dengan perdagangan benih, sistem penyimpanan benih, dan sistem transportasi benih udang. Pemesanan induk di Hawai dilakukan 1 bulan sebelumnya dengan harga beli induk sebesar US\$60-US\$65 per ekor dengan cara pembayaran secara cash. Minimal pemesanan induk sebanyak 3.000 pasang untuk jadwal pemakaian yang sudah ditentukan. Induk udang vaname yang berasal Hawai tersebut selanjutnya dikirim ke Carita dan Singaraja untuk dikembangbiakan dan selanjutnya dikirim ke PT Suri Tani Pemuka (STP). Pada masa pengembangbiakan, setiap satu indukan akan menghasilkan telur induk sebanyak 200 ribu sampai 300 ribu ekor. Indukan tersebut bertelur sebanyak 6-8 kali selama tiga bulan. Benih yang dijual adalah benih dengan ukuran PL10 yang masa pembenihannya selama 18 hari dan dijual

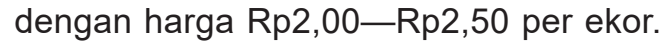

\section{Pembesaran}

Pada umumnya, pedagang mengambil panen udang dari 2-10 pembudi daya setiap hari dengan harga yang sudah disepakati terlebih dahulu. Harga yang berlaku tersebut berdasarkan harga pabrik yang dilakukan per minggu. Pembudi daya biasanya menjual hasil panen ke pedagang pengumpul yang dilakukan di lokasi tambak, sehingga pembudi daya tidak mengeluarkan biaya transportasi (biaya angkut) dan tidak mengeluarkan biaya untuk penggunaan es. Biaya transportasi (biaya angkut) dan penggunaan es semua ditanggung oleh pembeli (pedagang pengumpul). Jadi harga yang diterima oleh pembudi daya merupakan harga bersih. Udang dibeli dari pembudi daya dalam kondisi kering (tidak di es), dan dijual setelah di es, karena bobot udang akan naik sekitar $6 \%-7 \%$ setelah di es. Cara pembayaran dilakukan oleh pedagang ke petambak biasanya dalam 3 hari setelah panen diambil atau ada juga pembayaran cash, sedangkan cara pembayaran dari pabrik biasanya 15 hari setelah barang diantarkan ke pabrik. Berikut ini harga udang yang dijual pembudi daya ke pedagang besar (supplier) di Kabupaten Indramayu.

Tabel 3. Harga Udang di Kabupaten Indramayu, 2019.

\begin{tabular}{cccc}
\hline \multirow{2}{*}{ Grade } & \multicolumn{3}{c}{ Harga Udang (Rp/kg) } \\
\cline { 2 - 4 } & $\begin{array}{c}\text { Awal } \\
\text { Tahun }\end{array}$ & $\begin{array}{c}\text { Tengah } \\
\text { Tahun }\end{array}$ & $\begin{array}{c}\text { Akhir } \\
\text { Tahun }\end{array}$ \\
\hline Ukuran 100 & 45.000 & 41.000 & 47.500 \\
Ukuran 90 & 49.000 & 45.000 & 51.000 \\
Ukuran 80 & 52.500 & 48.000 & 54.500 \\
Ukuran 70 & 57.000 & 52.000 & 58.500 \\
\hline
\end{tabular}

Sumber: Data Primer Diolah, 2019

Tabel 3 menunjukkan perbedaan harga udang pada periode awal, tengah, dan akhir tahun berdasarkan ukuran udang. Pada ukuran udang 100 sampai dengan ukuran udang 70 , harga udang semakin tinggi. Sebagai contoh, pada ukuran udang 100, harga udang pada awal tahun sebesar Rp45.000,00/kg, ukuran 90 sebesar Rp49.000,00/ $\mathrm{kg}$, ukuran 80 sebesar $R p 52.500,00 / \mathrm{kg}$, dan ukuran 70 sebesar $R p 57.000,00 / \mathrm{kg}$, begitu pula pada periode tengah dan akhir tahun. Hal lain yang mempengaruhi harga udang adalah perayaan hari raya dan Imlek.

\section{Sistem Penyimpanan}

\section{Pembenihan}

Penyimpanan benih menggunakan styrofoam, di dalam styrofoam benih dimasukkan 
dalam plastik, oksigen, dan karet. Biaya yang dikeluarkan sebesar Rp5,00—Rp6,00 (biaya pengemasan total). Jadi bahan-bahan yang digunakan dalam penyimpanan benih selain styrofoam adalah plastik, oksigen, dan karet. Biaya 1 styrofoam sebesar Rp35.000,00; dalam 1 styrofoam berisi 15 ribu ekor.

\section{Pembesaran}

Udang yang diperoleh dari pembudi daya, selanjutnya disimpan dalam coolbox yang memiliki kapasitas tertentu. Jumlah coolbox yang digunakan tergantung dengan volume udang yang diperoleh dari pembudi daya. Biasanya untuk 1 (satu) coolbox memiliki kapasitas 12 kuintal. Selain coolbox, dibutuhkan es untuk menjaga kualitas udang karena konsumen lebih menyukai produk yang memiliki kualitas udang yang tinggi (Hidayatullah et al., 2016). Penambahan es dalam coolbox tersebut tidak hanya menjaga kualitas udang tetapi juga dapat menaikkan bobot udang sebesar $6 \%-7 \%$. Ketentuan penggunakan es dalam coolbox adalah dengan perbandingan untuk 1 kuintal udang diperlukan $2 \mathrm{~kg}$ es.

\section{Sistem Transportasi}

\section{Pembenihan}

Perusahaan pembenihan udang vaname selama ini biasanya mendekati pasar. PT STP merupakan perusahaan pembenihan udang vaname yang memiliki wilayah pemasaran mencakup wilayah Jawa Tengah dan Yogyakarta sebesar 40\%, wilayah Jawa Barat (Indramayu, Cirebon, Garut, dan Karawang) sebesar 30\% , wilayah Jawa Timur (Pacitan), Sumatra, dan Banten masing-masing sebesar $10 \%$.

Berdasarkan Tabel 4, terlihat bahwa sebagian besar distribusi udang ke berbagai daerah yang menjadi pasar tujuan menggunakan moda transportasi darat, yaitu mobil dan truk dengan wilayah pemasarannya Jawa Barat, Jawa Tengah, dan Jawa Timur membutuhkan biaya distribusi Rp1.000.000,00-Rp2.500.000,00 dengan waktu tempuh yang dibutuhkan tergantung daerah tujuan.

\section{Pembesaran}

Pedagang besar/supplier yang menyimpan udang selanjutnya mendistribusikannya ke Unit Pengolahan Ikan (UPI) dan konsumsi masyarakat di pasar lokal dan pasar luar kota. Beberapa variabel yang digunakan pada sistem transportasi adalah moda transportasi, biaya distribusi, dan waktu tempuh. Sistem transportasi ini memberikan kontribusi pada produksi, harga, dan pasar (Ballou, 2004). Tabel 5 menunjukkan pasar tujuan dilihat dari biaya distribusi dan waktu tempuh yg diperlukan.

Berdasarkan Tabel 5, sebagian besar udang yang berasal dari Kabupaten Indramayu didistribusikan ke pasar tujuan, yaitu pasar lokal, Jawa Barat, dan Jakarta dengan menggunakan moda transportasi mobil di wilayah pemasaran Jawa Barat dan Jakarta serta alat transportasi motor di wilayah pasar lokal Indramayu. Waktu tempuh yang dibutuhkan tergantung daerah tujuan

Tabel 4. Biaya Distibusi Benih di Kabupaten Indramayu, 2019.

\begin{tabular}{|c|c|c|c|}
\hline Pasar Tujuan & $\begin{array}{c}\text { Alat } \\
\text { Transportasi }\end{array}$ & $\begin{array}{c}\text { Biaya Distribusi } \\
\text { Rp/kg }\end{array}$ & WaktuTempuh \\
\hline Jawa Tengah & Truk & 450 & 8-10 jam \\
\hline Yogyakarta & $\begin{array}{l}\text { Truk } \\
\text { Mobil }\end{array}$ & $\begin{array}{r}500 \\
1.300\end{array}$ & 8-10 jam \\
\hline Jawa Timur (Pacitan) & Mobil & 2.100 & 18-20 jam \\
\hline Jawa Barat (Cirebon, Garut, Karawang) & Mobil & 850 & 1-2 jam \\
\hline
\end{tabular}

Sumber: Data Primer Diolah, 2019

Tabel 5. Biaya Distribusi Udang yang Dikeluarkan ke Pasar Tujuan, 2019.

\begin{tabular}{lccc}
\multicolumn{1}{c}{ Daerah Pemasaran } & Alat Transportasi & Biaya Distribusi(Rp/Kg) & Waktu Tempuh \\
\hline Bandung & Mobil & 850 & 3 jam \\
Jakarta (Muara Baru, Muara Angke) & Mobil & 1.375 & 6 jam \\
Pasar Lokal/Pengecer & Motor & 50 & 1 jam \\
\hline
\end{tabular}

Sumber: Data Primer Diolah, 2019 
berkisar antara $1-3$ jam untuk pasar lokal dan Jawa Barat, sedangkan untuk pasar tujuan Jakarta dibutuhkan waktu tempuh selama 6 jam. Biaya distribusi yang dikeluarkan dengan menggunakan moda transportasi darat tersebut berkisar antara Rp50,00 per kg untuk pasar lokal; Rp850,00 per kg untuk pasar tujuan Bandung (Jawa Barat); serta Rp1.375,00 per kg untuk pasar tujuan Jakarta.

\section{PENUTUP}

Kinerja rantai pasok komoditas udang di Kabupaten Indramayu dilihat dari efektivitas dan efisiensi. Efektivitas rantai pasok udang di Kabupaten Indramayu, Provinsi Jawa Barat mengalami peningkatan dari sisi produksi, yaitu sebesar $18,45 \%$ pasokan udang di Kabupaten Indramayu dapat memenuhi permintaan UPI udang yang ada di Jawa Barat. Efisiensi rantai pasok udang terlihat pada indikator disparitas harga dan margin harga. Disparitas harga terbesar terjadi pada ukuran udang $\mathbf{S 1 0 0 ,}$ yaitu sebesar $6 \%$, sedangkan disparitas harga terkecil terjadi pada udang dengan ukuran S70, yaitu sebesar $3 \%$. Margin harga terjadi pada setiap simpul dalam rantai pasok udang; margin harga untuk ukuran udang S170 adalah pedagang kecil $3 \%$ dan pengecer $22 \%$; pada ukuran udang $\mathrm{S} 100$, margin harga yang terjadi adalah pedagang kecil $4,3 \%$ dan pedagang besar $2 \%$. Terkait dengan manajemen logistik, biaya distribusi yang dikeluarkan masih tinggi. $\mathrm{Hal}$ ini terjadi karena intensitas distribusi udang ke pasar tujuan yang dilakukan setiap hari, sehingga menyebabkan biaya distribusi relatif tinggi. Oleh karena itu, perlu perbaikan dalam sistem manajemen logistik komoditas udang terkait dengan proses pengadaan, penyaluran, dan sistem penyimpanan, serta transportasi diatur dengan sistem yang terorganisasi dengan baik agar efektif dan efisien.

\section{UCAPAN TERIMA KASIH}

Penulis mengucapkan terima kasih kepada Balai Besar Riset Sosial Ekonomi Kelautan dan Perikanan yang telah memberikan pendanaan dalam kegiatan ini; Dinas Kelautan dan Perikanan Provinsi Jawa Barat, Dinas Kelautan dan Perikanan Kabupaten Indramayu, serta rekan-rekan peneliti yang terlibat dalam penelitian Model Penerapan Sistem Logistik Perikanan Budi Daya dan Penggunaan DSS untuk Perikanan Budi Daya Berkelanjutan.

\section{PERNYATAAN KONTRIBUSI PENULIS}

Penulis menyatakan bahwa dalam pembuatan karya tulis ini, Risna Yusuf merupakan kontributor utama, sementara Asnawi, Rismutia Hayu Deswati, dan Lathifatul Rosyidah merupakan kontributor anggota.

\section{DAFTAR PUSTAKA}

Anonymous. (2013). Mengenal sistem logistik. https:// debbyrahmi.wordpress.com/2013/01/10/ mengenal-sistem-logistik

Apriani, H., Erliana, C. I., \& Zakaria, M. (2019). Analisis supply chain management (SCM) udang vaname di Desa Teupin Pukat Kabupaten Aceh Timur. SNTI 2019, Lhokseumawe 14-15 Oktober 2019. ISSN : 23387122.

Apriliani, T., Yusuf, R., Rosyidah, L., \& Zamroni, A. (2020). Kinerja rantai pasok udang vannamei di Provinsi Nusa Tenggara Barat. Prosiding Seminar Nasional Riset dan Kebijakan Sosial Ekonomi Kelautan dan Perikanan Tahun 2020, 121-131.

Assauri, S. (2011). Manajemen produksi dan operasi. Lembaga Penerbit FEUI.

Ballou, R. H. (2004). Business logistic supply chain management. Fifth Edition. Prentice Hall. Inc.

Badan Pusat Statistik Kabupaten Indramayu (BPS Kabupaten Indramayu). (2020). Kabupaten Indramayu dalam angka 2020. Badan Pusat Statistik.

Badan Pusat Statistik Kabupaten Indramayu (BPS Kabupaten Indramayu). (2021). Kabupaten Indramayu dalam angka 2021. Badan Pusat Statistik.

Chase, A., \& Jacobs. (2001). Operation management for competitive advantage (Int. Editions, 9th Edition). The Mc Graw-Hill//rwin Series.

Deswati, R. H., \& Muhadjir, M. (2015). Dukungan aspek produksi dalam sistem logistik ikan nasional (SLIN) di Kota Kendari, Sulawesi Tenggara. Jurnal Sosial Ekonomi Kelautan dan Perikanan, 10(2), 191-202. http://dx.doi.org/10.15578/jsekp. v10i2.1259

Deswati, R. H., Rosyidah, L., \& Apriliani, T. (2020). Pengaruh manajemen rantai pasok terhadap performa usaha budi daya udang vaname di Provinsi Bali dan Jawa Timur. Buletin Ilmiah Marina Sosial Ekonomi Kelautan dan Perikanan, 6(2), 113-124. http://dx.doi.org/10.15578/marina. v6i2.8474

Dinas Kelautan dan Perikanan Kabupaten Indramayu. (2018). Statistik perikanan Provinsi Jawa Barat. Pemerintah Daerah Provinsi Jawa Barat. 
Fitzsimmons, J. A., \& Fitzsimmons, M. J. (2006). Service management (International 5th Ed.). The McGraw-Hill Companies.

Harimurti, C. (2017). Model peningkatan kinerja sistem logistik yang efektif dan efisien. Jurnal Logistik Indonesia, 1(1), 46—67. https://doi.org/10.31334/ jli.v1i1.127.g112

Hidayatullah, Fatihudin, D., \& Salbiyah, S. (2016). Implementasi strategi pemasaran udang vannamei bagi petani tambak di Desa Noreh, Kecamatan Sreseh, Kabupaten Sampang. Balance, 8(2), 133-144. http://dx.doi.org/10.30651/blc. v13i02.1317

Heizer, J., \& Render, B. (2014). Operations management: Sustainability and supply chain management. Pearson Education.

Kementerian Perdagangan. (2011). Rantai pasok komoditas strategis. Laporan Teknis. Kementerian Perdagangan.

Mulyadi, D. (2011). Pengembangan sistem logistik yang efisien dan efektif dengan pendekatan supply chain management. Journal of Industrial Research (Jurnal Riset Industri), 5(3), 275-282.

Nazir \& Muhammad. (1988). Metode penelitian. Ghalia Indonesia.

Nuraini, N., Sarkum, S., \& Halim, A. (2021). Analysis of company capability, supply chain management of competitive advantage, and company performance. Indonesian Interdisciplinary Journal of Sharia Economics (IIJSE), 4(1), 87-104. https://doi.org/10.31538/iijse.v4i1.1463

Ongirwalu, D. J., Tumade, P., \& Palandeng, I. D. (2015). Evaluasi hilir rantai pasokan dalam sistem logistik komoditi cabai di Pasar Tradisional Pinasungkulan Manado. Jurnal EMBA: Jurnal Riset Ekonomi, Manajemen, Bisnis, dan Akuntansi, 3(1). https:// doi.org/10.35794/emba.3.1.2015.7804

Peraturan Presiden Republik Indonesia Nomor 26 Tahun 2012. (2012). Cetak biru pengembangan sistem logistik nasional. Buku Cetak Biru Pengembangan Sistem Logistik Nasional.

Rosyidah, L., Yusuf, R., \& Deswati, R. H. (2020). Sistem distribusi udang vaname di Kabupaten Banyuwangi, Provinsi Jawa Timur. Buletin IImiah Marina Sosial Ekonomi Kelautan dan Perikanan, 6(1), 51-60. http://dx.doi. org/10.15578/marina.v6i1.8540

Siahaya, W. (2013). Sukses supply chain management akses demand chain management. In Media.

Stevenson, W. J. (2009). Managemen operation. Prentice Hall.

Subroto, A. M., Kawet, L., \& Sumarauw, J. (2015). Evaluasi kinerja supply chain manajemen pada produksi beras di Desa Panasen Kecamatan Kakas. Jurnal EMBA: Jurnal Riset Ekonomi, Manajemen, Bisnis, dan Akuntansi, 3(1), 653-662. https:// doi.org/10.35794/emba.3.1.2015.7328

Sutanto, M. R., \& Sumarauw, J. S. (2014). Evaluasi kinerja sistem logistik pada perusahaan vulkanisir UD Sumber Ban, Tateli. Jurnal EMBA: Jurnal Riset Ekonomi, Manajemen, Bisnis, dan Akuntansi, 2(3), 588-596. https://doi. org/10.35794/emba.2.3.2014.5624

Syahputra, I., Susanti, E., \& Hakim, L. (2018). Strategi rantai pasok udang vaname pada PT Aryazzka Indoputra Kabupaten Aceh Besar. Jurnal IImiah Mahasiswa Pertanian, 3(4) 342-354. https://doi. org/10.17969/jimfp.v3i4.9492

Tajerin, Muhadjir, \& Deswati, R. H. (2015). Model pengembangan sistem logistik ikan nasional terintegrasi MP3El dan sistem transportasi melalui pendekatan pengadaan stok ikan. Laporan Teknis. Balai Besar Riset Sosial Ekonomi Kelautan dan Perikanan. Tidak dipublikasikan.

Untsayain, A. M., Mu'tamar, M. F. F., \& Fakhry, M. (2017). Analisis pasokan udang di Kabupaten Sidoarjo (Studi Kasus UD Ali Ridho Group). Industria: Jurnal Teknologi dan Manajemen Agroindustri, 6(3), 119-125. https:// doi.org/10.21776/ub.industria.2017.006.03.2

Vorst, V. D. (2006). Performance measurement in agri-food supply chain networks. Netherlands: Logistics and Operations Research Group. Wageningen University.

Yusuf, R., \& Hikmayani, Y. (2017). Minimalisasi biaya distribusi industri pengolahan produk perikanan: Aplikasi transportasi program solver. Jurnal Sosial Ekonomi Kelautan dan Perikanan, 12(2), 151-162. http://dx.doi.org/10.15578/jsekp. v12i2.6480

Yusuf, R., Rosyidah, L., Zamroni, A., \& Apriliani, T. (2020). Rantai pasok dan sistem logistik udang vaname di Kabupaten Pinrang, Provinsi Sulawesi Selatan. Buletin IImiah Marina Sosial Ekonomi Kelautan dan Perikanan, 6(1), 25-35. http:// dx.doi.org/10.15578/marina.v6i1.8494

Zamroni, A., Yusuf, R., Apriliani, T., Asnawi, Deswanti, R. H., Indah, B. V., \& Rosyidah, L. (2019). Riset model penerapan sistim logistik perikanan budi daya serta penggunaan DSS untuk perikanan budi daya berkelanjutan. Laporan Teknis. Balai Besar Riset Sosial Ekonomi Kelautan dan Perikanan. 